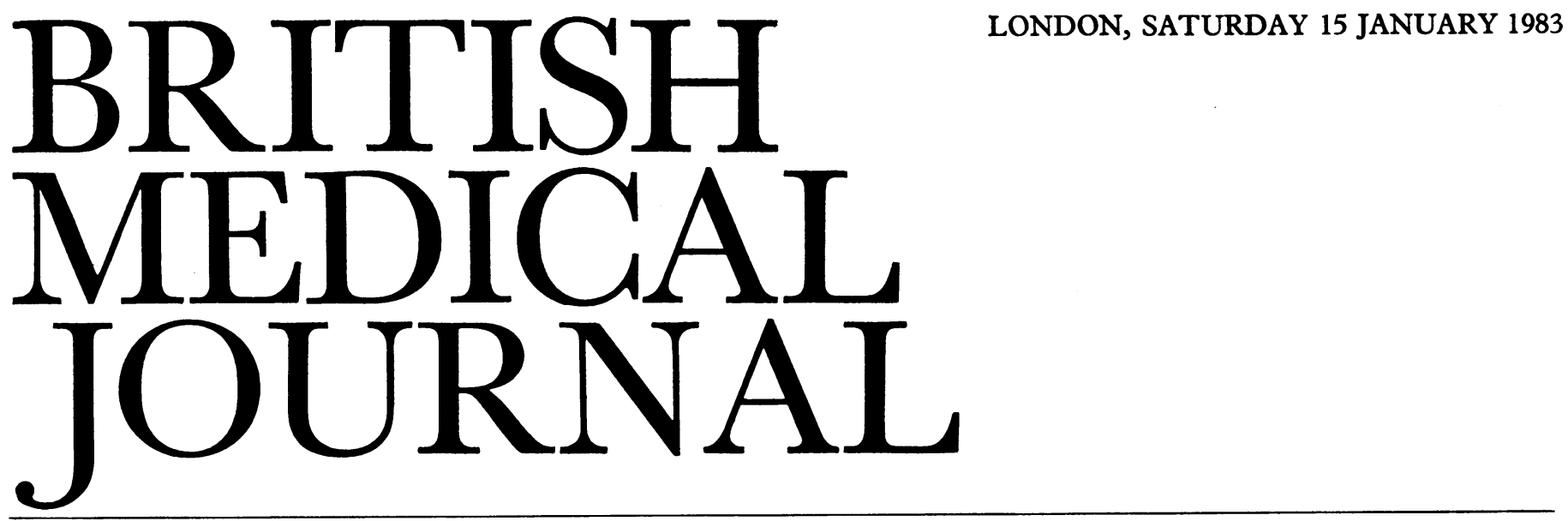

\title{
Smoking in patients with advanced lung disease
}

People stop smoking for various reasons-financial, social, or medical-and often for a combination of the three. Yet despite the force of reason the man in the street is still likely to wait until symptoms develop before heeding the arguments. ${ }^{1}$ Most patients will stop smoking after a myocardial infarct if the advice is given with conviction and firmness. ${ }^{2}$ Surgery for lung cancer might also be expected to discourage most patients from smoking, but a recent survey showed that $48 \%$ of patients alive five years after surgery had restarted smoking, usually within a year of operation. ${ }^{3}$ Ironically, it is the patients with inoperable lung cancer who often lose their taste for cigarettes.

The insidious development of chronic bronchitis and emphysema ensures that patients have minimal symptoms until the disease is fairly extensive. The initial changes in alveoli and small airways cause few symptoms and little change in the forced expiratory volume in one second $\left(\mathrm{FEV}_{1}\right)$. Even the progressive decline of the $\mathrm{FEV}_{1}$ is usually associated with minimal symptoms until it has fallen to 1.5 litres or below. Any small further drop in the $\mathrm{FEV}_{1}$ then brings a large increase in symptoms.

Cigarette smoking is associated with an increased mortality from chronic bronchitis and emphysema ${ }^{4}$ and with an increased annual rate of decline in $\mathrm{FEV}_{1}$ or $\mathrm{FEV}_{0.75}{ }^{5-7}$ Studying working men in London over 10 years, Fletcher et al found a mean annual fall in $\mathrm{FEV}_{1}$ of $36 \mathrm{ml}$ in non-smokers compared to $78 \mathrm{ml}$ in those smoking more than 15 cigarettes a day. ${ }^{6}$ A few smokers, however, showed a much more rapid decline: $11 \%$ had a fall in $\mathrm{FEV}_{1}$ above $90 / \mathrm{ml} /$ year (1 litre in 11 years), and clearly these were destined for disabling airways obstruction.

How much benefit can be gained by patients from stopping smoking once airways obstruction is present? We know that working men who stop smoking have a decreased morbidity compared with those who continue to $\operatorname{smoke}^{78}$ as well as a lower annual fall in $\mathrm{FEV}_{1}{ }^{6}$ Nevertheless, some studies in patients with chronic bronchitis (as opposed to working men) have not shown any substantial benefit from stopping smoking. ${ }^{910}$ This lack of effect could be due to the relatively small numbers or short follow-up, but probably more important is that some ex-smokers will have stopped smoking because they had severe disease. This appeared to be the case with British doctors, among whom ex-smokers had a higher mortality from chronic bronchitis than current smokers for up to nine years after stopping smoking. ${ }^{11}$ After nine years, however, mortality in ex-smokers was substantially reduced compared with smokers. The reason why patients stop smoking is crucial to the interpretation of epidemiological studies on smoking. Unlike drug studies people cannot be prospectively randomised to a smoking or ex-smoking group.

A recent study by Hughes et al has looked again at this problem in patients with emphysema. ${ }^{12}$ The rates of decline of $\mathrm{FEV}_{1}$ and vital capacity over three years were compared in 37 patients who smoked when the study started in 1976, with 19 ex-smokers, excluding any who restarted smoking during the study. The patients had a mean age of 55, a mean $\mathrm{FEV}_{1}$ of $52 \%$ of the predicted value, had smoked over $200 \mathrm{~kg}$ of tobacco, and most had moderate dyspnoea and some production of sputum. They therefore appear to have had a mixture of chronic bronchitis and emphysema with some airways obstruction. There was a significant difference in the rate of decline of $\mathrm{FEV}_{1}$ between the two groups $-53 \mathrm{ml} /$ year in the current smokers but only $16 \mathrm{ml} /$ year in the ex-smokers. The authors conclude that stopping smoking in patients with moderately severe airflow obstruction will slow down the development of airways obstruction. This conclusion, as always, presupposes that the only difference between the two groups was the difference in current smoking habits. The ex-smokers had a slightly lower $\mathrm{FEV}_{1}$ and vital capacity and a higher transfer coefficient for carbon monoxide than the smokers. The ex-smokers may therefore have had more bronchial disease and the smokers more emphysemadifferences which might have some effect on the rate of decline. The large difference between the two groups is, however, much more likely to be due to differences in smoking.

Why do these results differ from the negative findings in previous studies of stopping smoking in patients ? ${ }^{910}$ The most likely reason is that the patients studied by Hughes et al had less severe airways obstruction and so had stopped smoking at an earlier stage of their disease. The results of the study of British doctors suggested that if patients wait until symptoms are severe stopping smoking will not prevent death from chronic bronchitis. ${ }^{11}$ Whether it delays death at this stage is more difficult to ascertain.

Epidemiological studies on smoking rarely provide clear answers, but this one provides further evidence to support the view that stopping smoking will cause a very worthwhile reduction in the rate of decline in pulmonary function in 
patients with moderate airways obstruction. In conjunction with the results of other studies the implication is that the sooner smoking is stopped the better; patients who wait too long may not only run out of breath but out of time.

\section{ANNE E TATTERSFIELd}

Reader in Medicine,

University of Southampton,

Southampton General Hospital,

Southampton SO9 $4 \mathrm{XY}$

${ }^{1}$ Jones JS. Cigarette abandonment: its significance. $\operatorname{Br} \mathcal{F}$ Dis Chest 1977; $71: 285-8$.

${ }^{2}$ Burt A, Thornley P, Illingworth D, White P, Shaw TRD, Turner R. Stopping smoking after myocardial infarction. Lancet 1974 ; : $: 304-6$.

3 Davison G, Duffy $M$. Smoking habits of long-term survivors of surgery for lung cancer. Thorax 1982;37:331-3.

4 Doll R, Hill AB. Mortality in relation to smoking: ten years' observations of British doctors. Br Med F 1964; ; 1399-410.

${ }^{5}$ Bates DV. The fate of the chronic bronchitic: a report of the ten-year follow-up in the Canadian department of Veteran's affairs co-ordinated study of chronic bronchitis. Am Rev Despir Dis 1973;108:1043-65.

${ }^{6}$ Fletcher CM, Peto R, Tinker C, Speizer FE. The natural history of chronic bronchitis and emphysema. Oxford: Oxford University Press, 1976.

${ }^{7}$ Huhti E, Ikkala J. A 10-year follow-up study of respiratory symptoms and ventilatory function in a middle-aged rural population. Eur $\mathcal{F}$ Respir Dis $1980 ; 61: 33-45$.

$\checkmark$ Sharp JT, Paul O, McKean H, Best WR. A longitudinal study of bronchitic symptoms and spirometry in a middle-aged, male, industrial population. Am Rev Respir Dis 1973;108:1066-77.

${ }^{9}$ Burrows B, Earle RH. Course and prognosis of chronic obstructive lung disease. A prospective study of 200 patients. $N$ Engl f Med 1969;280: 397-404.

10 Johnston RN, McNeill RS, Smith DH, Legge JS, Fletcher F. Chronic bronchitis-measurements and observations over 10 years. Thorax 1976 ;31:25-9.

11 Doll R, Peto R. Mortality in relation to smoking: 20 years' observations on male British doctors. Br Med $\mathcal{F} 1976$;ii:1525-36.

${ }^{12}$ Hughes JA, Hutchison DCS, Bellamy D, Dowd DE, Ryan KC, HughJones $P$. The influence of cigarette smoking and its withdrawal on the annual change of lung function in pulmonary emphysema. $Q \mathcal{F ~ M e d}$ $1982 ; 202: 115-24$.

\section{Consequences of intrauterine growth retardation}

The baby who is small for gestational age at birth is seen in different ways by doctors in different disciplines. The obstetrician's concern is directed towards causation, ${ }^{1}$ and placental failure towards the end of gestation carries for him intimations of mortality. That is why the therapeutic option of delivering a growth retarded baby prematurely for better nourishment in the neonatal unit looks attractive. The paediatricians who care for such children after they have been safely born look at them from a different angle. Their concerns are the longer term consequences of low birth weight-which are often underestimated.

In the newborn nursery feeding these infants may be difficult because they can consume only small volumes of food; attempts to mimic the intrauterine growth rate are seldom successful. ${ }^{2}$ It is unfortunately true that whenever the growth rate is reduced without a commensurate delay in maturation the prognosis for ultimate growth is irreversibly reduced. Every day that goes by in infancy with an abnormal growth rate leads to stunting in later childhood and adult life.

Infants who are small for gestational age are far from homogeneous in their physical appearance at birth. Short lived starvation in utero-the nightmare for the obstetrician-leads to a length which is appropriate for gestational age and a weight which is reduced because of the loss of adipose tissue and muscle. These babies do genuinely "catch up" their weights, but their growth in length was never seriously compromised The child that causes the paediatrician concern is the one with evidence of more prolonged fetal growth retardation, detected by reduction of weight, length, and head circumference, in thaE order according to severity. Proper assessment of the growth retarded infant thus requires the accurate measurement of length, and special care nurseries must be provided with then requisite equipment. ${ }^{3}$ Sadly, though much attention is paid toे. weighing babies-a first approximation to measurement of length-most babies in Britain get measured with a tap measure if they are lucky.

Children of low birth weight have long been recognised tọ show considerable diversity in the way they grow, ${ }^{4}$ but th 8 optimistic view that delay in maturation would help ultimatel to overcome intrauterine growth retardation ${ }^{5}$ looks increasingly doubtful. ${ }^{6}$ The stigmata of low birth weight persist to adul? life. ${ }^{7}$ None of this is particularly surprising when we conside $\vec{E}$ that growth is bound to be more vulnerable when it is at it? most rapid and that about one third of total growth in height has already been achieved by the time of birth.

Perhaps these theoretical considerations have little practica impact on the day to day practice of health clinics, but al\& workers with children will echo the fact that the child who feeds badly places a tremendous strain on the mother-chilक relationship. Giving food to a child is the most basic of maternat instincts, and when the child frustrates attempts to feed it the consequences may range from unhappiness to physical injury? Though many feeding problems simply reflect the fact that child may not take as much food as its parents would like growth retarded infants are genuinely very difficult to feed. S long as measurements show them to be growing at a normate rate there is much to be said for sympathetic reassurance rathefi than highlighting what appears to be an inadequate gain in weight. Indeed, much good would come if weighing childre was abandoned; for-like taking their temperatures-it ma divert attention from their obvious clinical condition.

Growth retardation may also be acquired after birth. Wit more infants surviving medical and surgical conditions of increasing complexity, those who care for them must be conscious of the long term consequences of not maintaining adequate growth rates. Perinatal growth retardation is one of. the commoner causes of referral in later childhood to a growt disorder clinic: such children should be protected agains extensive investigation for "failure to thrive" when they ar: actually thriving at the time they are referred. The explanation for their growth retardation, which lies in the previous history? is not generally susceptible to biochemical verification.

In an age when the number of children born to a family i용 expected to decrease the health and wellbeing of those fer children are at a premium. Obstetricians must be provided with the wherewithal to diagnose fetal wellbeing and not be limite to a single ultrasound scan in pregnancy for estimating gestae tional age. Only by closely monitoring pregnancies of growtho retarded infants can we learn to identify the preventable cause? of growth retardation and optimise the growth and develop? ment of the coming generation.

Consultant Paediatrician,

Charles G D Broo: $\stackrel{0}{\vec{k}}$

Middlesex Hospital,

London W1N 8AA

1 Howie $\mathrm{PW}$. Causes of intrauterine growth retardation. Br Med f $1982 ; 285$ 156-7.

2 Fomon SJ. Infant nutrition. Philadelphia. W B Saunders Co, 1974;49£

3 Davies DP, Holding RE. Neonatometer: a new infant length measurex Arch Dis Child 1972;47:938-40.

- Fitzhardinge PM, Steven EM. The small-for-date infant. I. Later growt patterns. Pediatrics 1972;49:671-81. 